\title{
What about a (really) minimalist theory of language acquisition?*
}

\author{
VÍCTOR M. LONGA AND GUILLERMO LORENZO
}

\section{Abstract}

The Minimalist Program introduced a new concept of language and added new content to the innateness position concerning our linguistic capacity. It also redefined the metatheoretical role of the theory of acquisition within generative grammar. This article explores at length all these issues and offers a critical survey of the disconcerting situation dominating today's relationship between syntacticians and acquisitionists.

\section{Introduction}

The emergence and the development of the Minimalist Program (MP) provoked a change in how we judge the explanatory adequacy of the principles attributed to the human faculty of language. We no longer consider these principles good candidates for inclusion in the linguistic capacity a child makes use of in constructing a grammar from an opaque and fragmentary stimulation; rather we look at their adequacy as optimal solutions for the needs imposed by the cognitive systems that language is supposed to serve as a sort of bridge. Apparently, those who investigate language acquisition have answered to this shift by ignoring or only superficially attending to the theoretical challenges introduced by the MP. It is not the aim of this article to claim that this situation is to be explained by the displacement of matters of acquisition to a secondary position within generativism. We shall simply try to describe the state of the art in the field as well as to put forward some ideas on how to focus the study of acquisition in accordance with the minimalist conception of human language.

The article is organized as follows: Section 2 attempts to clarify the value of the classical "Poverty of Stimulus Argument" and to show that its real argumentative power is in agreement with the position in which 
the MP places the questions related to the acquisition of language. This very section examines the notion of "innateness" and explores a partial redefinition of it motivated by the main minimalist contentions about language. Section 3 tries to show that recent research in the field of language acquisition seems in general (and in its essence) not to observe the crucial theoretical challenges brought into linguistics by minimalism. In order to reach this goal we have done a careful examination of the most relevant articles on acquisition published during the years 2001 and 2002. Section 4 summarizes the main ideas of our article and comments on the current divide between syntactic theory and acquisition theory, an undesirable situation although utterly significant, as it illustrates the confusion into which the MP seems to have driven linguistic theorizing.

\section{Innateness and Poverty of Stimulus in the Minimalist Program}

The Poverty of Stimulus Argument (henceforth, PS argument), whose ultimate formulation is usually attributed to Chomsky (1980), ${ }^{1}$ is generally accepted as the strongest foundation of the nativist position held by generative grammarians about human language. ${ }^{2}$ The truth is that the argument has been misinterpreted by many, especially by those who think that proving its falsity is the most effective way to discredit generativism. For this reason, we will devote the following pages to clarifying the content of the argument and its weight in support to the innateness thesis. We will also dedicate some pages to rethinking and reformulating this thesis in the light of the central contentions of the MP and of some recent debates on the philosophy of biology.

\subsection{Some thoughts on the argumentative power of the Poverty of Stimulus Argument ${ }^{3}$}

The PS argument tries to capture the contrast between, on the one hand, the kind of data accessible to children in the process of acquiring their mother tongue and, on the other, the grammatical competence they arrive at as the result of that process. The basic tenet of the argument is that the amplitude and rich articulation of the knowledge about language of any normal child strongly contrasts with the scarcity and degeneracy of the data she comes across. Actually, the deficiencies of the data are of different kinds, which Thomas (2002) classifies into three main groups, each of them reflecting a different sense of the term "poverty" normally used in this respect: ${ }^{4}$ 
1. Degeneracy. Stimuli are poor because they contain defects such as false starts, interrupted fragments, lapses, etc.

2. Finiteness. Stimuli are poor because they represent a very limited, idiosyncratic, and accidental array of data from an infinite set of possibilities.

3. Partiality. Stimuli are poor because certain phenomena that the child has no problems dealing with are completely absent from the array of data at her disposal.

Thomas considers that the third aspect of the term has become its central sense for most commentators of the PS argument, with the other being progressively left in the background. This opinion seems to us essentially correct, but it is important to note that the PS argument has also to do with the absence or the scarcity of "negative evidence", i.e., marks on which the child could base the conclusion that certain utterances are not acceptable in the adult grammar. This fact is of enormous interest, because the child could never reach this kind of conclusion from a finite and partial array of data (see Fodor and Crowther [2002], as well as the extensive bibliography on the matter that they offer). The PS argument is also to be related with the fact that the rich and complex internal articulation of any utterance is something an individual cannot be aware of by simply observing its surface. Sentences do not mark their potential structural ambiguity, the conjoint or disjoint reference of their components and so on, and they only contain vague indications of the hierarchical structure hidden behind an otherwise lineal arrangement of items (see Crain and Pietroski 2002). It is also important to notice that certain elements of the stimuli can be considered quantitatively poor in the sense of not being persistent enough as to trigger the acquisition of the relevant aspects of grammar (see Legate and Yang 2002).

The progressive identification of "poverty" with "partiality", commented on by Thomas, is, from our point of view, to be explained as an effect of the attention paid to this aspect of the PS argument by its critics rather than as a real evolution in the contents of the argument itself, as it can be observed in articles like Pullum and Scholz (2002) and Sampson (2002). Pullum and Scholz denounce that not enough effort has been devoted to recording grammatical phenomena that are indisputably absent from the stimuli typically offered to children: therefore, the PS argument, in their opinion, is still waiting for confirmation. Sampson defends (with no special effort of documentation) that any grammatical phenomenon can be considered to be present in any representative sample of the linguistic practices of a community: therefore, the PS argument is, Sampson claims, false, as well as any theoretical consequence that one would wish 
to derive from it. However, as we have shown, the PS argument does not reduce to this aspect, so questioning it is not enough to cast doubts on the whole argument.

We will not go further into this debate. Our central aim in the remainder of this section will be to show that criticisms of the PS argument intended to question the nativist position of generative grammar rely on serious misunderstandings of the contents of the argument and of its power in defense of that position. Let us start by examining a fallacy in the argument put forward by Sampson (2002). He notices (correctly) that the PS argument and the innateness hypothesis are related by logical implication (PS $\rightarrow$ innateness), but he claims that the PS argument has no empirical support. Sampson recognizes that the latter is not enough to refute the innateness thesis, but in spite of this awareness, he concludes that innateness is a "novel and surprising proposition", one that any reasonable person should reject without the support of any well-established fact (Sampson 2002: 97). Actually, what any reasonable person should accept is that, even if stimuli were rich enough as to allow a data-driven learning mechanism, such a fact would not decide by itself the question about the procedure children really make use of when they learn to speak. It happens that the implication $P S \rightarrow$ innateness has no real argumentative role in the reasoning presented by Sampson, whose real strategy (obviously, a fallacy) relies on presenting innateness as extravagant. ${ }^{5}$

What critics of the PS argument seem not to understand is that if the argument proved to be unsound, only the contention that stimuli are poor should be rejected, with innateness remaining as legitimate a thesis as before. The reason is that the PS argument (contrary to what is normally assumed) is not (or at least not directly) a "pro-innateness" argument, but an "anti-empiricism" one. The power of the argument relies on the fact that any effort to explain language acquisition as a process guided from stimuli and the external circumstances of the child must be abandoned if it proves to be correct. If, on the contrary, stimuli are proved to be rich and capable of serving as the model from which to derive any sort of grammatical rule or principle, then an empiricist interpretation of language learning is in principle possible. However, even so, this does not mean that this interpretation would be the only theoretical alternative. One must never forget that a process guided by the internal resources of the organism is possible irrespective of the richness or poorness of stimuli. ${ }^{6}$

In other words, the PS argument is not a knife with two edges. It has only one that threatens data-driven or empiricist theories of language acquisition. It is certainly true, as pointed out by Pullum and Scholz, that "casting doubt on alleged PS argument cases [...] undercuts skepticism 
about data-driven learning" (Pullum and Scholz 2002: 46). That is all. The fact that a theory can be considered possible to get around does not imply that competing theories have lost their own legitimacy. Theories are not required to monopolize in order to be worthy of credit.

\subsection{The position of the PS argument within the Minimalist Program}

The ideas of the previous subsection lead us to conclude that the PS argument has only an indirect or secondary role in the defense of innateness, because its main argumentative value is to discredit empiricism. It is our opinion that this conclusion is related to one of the contentions of the MP, according to which the results of language acquisition theory are also of a secondary interest in relation to the explanatory aims of linguistic theory (see Chomsky 2000, 2001; see also below). This contention seems rather surprising if one thinks of the central position of acquisition matters within previous models of generative grammar, which acknowledged explanatory adequacy to theories of grammar attending to their credit as an hypothesis concerning the initial state of linguistic knowledge children make use of when learning to speak. Let us remember Chomsky's own words:

The problem of internal justification - of explanatory adequacy — is essentially the problem of constructing a theory of language acquisition, an account of the specific innate abilities that make this achievement possible. ${ }^{7}$ (Chomsky 1965: 27)

The MP has shifted the criterion of explanatory adequacy, and theories are now evaluated according to their capacity to account for the adjustment of the Faculty of Language (henceforth, FL) to the cognitive modules that it is supposed to connect with: on the one hand, the systems of thought by which we represent the external world or we figure out the mental states of other people, and, on the other, the sensory-motor systems by which we exteriorize and internalize the signals containing our and other people's thoughts. Under the (not uncontroversial) claim that the design of the FL aims to serve as an optimal channel, the MP contends that the best version of it will be that which offers the most immediate or direct connection between these two nonlinguistic modules, with a minimum of (and, ideally, with no) specific grammatical machinery. At the same time, the best theory of language will be the one capable of modeling the FL according to the corresponding ideal: that is, attending above all to the properties of the external systems and avoiding grammatical notions and categories as much as possible. Chomsky declares that if 
theories conducted in this way happen to find support from the results of neurophysiology or language acquisition research, this will be good news, but he also declares that these questions are "irrelevant in principle" (Chomsky 2000: 96). This means that they are not recognized as capable of deciding among competing theories. ${ }^{8}$

Let us think again about the PS argument. It seems clear that its position within the argumentative depot of the MP cannot be a central one. That stimuli given to children are or are not poor is not directly related with the main guidelines of the program, i.e., that language development consists above all in the coupling of two cognitive systems of a very different nature. Within this framework, the ultimate goal of the theory from the point of view of evolutionary psychology would be to discover how those systems instruct the implementation of a linguistic system connecting them. If a solution to this question also happens to be a solution to the problem of how children manage to undergo the process of acquiring a language without the help of their environment, so much the better for the theory. However, it is clear that the question about the richness or the poverty of stimuli will be unessential to a theory aimed at solving the problems of language development embracing the thesis of the MP.

\subsection{On the grammatical specificity of the innate universal base}

The MP also makes us question what kind of knowledge we can reasonably consider innate and even to rethink the very concept of innateness. The broadly accepted contention of generativist grammarians up to the nineties was that a well-defined and richly structured set of specifically grammatical knowledge was attributable to children prior to any linguistic experience. However, the explanatory guidelines of the MP lead us to reduce (and, ideally, to eliminate) the grammatical machinery used to describe the human faculty of language (see Lorenzo and Longa 2003: Sections 2 and 3). Under the assumptions made by the MP, the FL mainly consists of ensembles of conceptual-intentional and sensory-motor units provided by the external systems (lexical items), ready to be combined by a computational procedure (syntax) whose functioning is governed by principles of an enormous simplicity (binary merging, asymmetric projection, minimal movements or links, and so on), none of which should be considered as extravagant grammatical criteria. What this actually means is that the nature of the FL is not different from that of the external systems. ${ }^{9}$ It continues to be a universal and, conceivably, innate base, but nevertheless not a specifically grammatical one. Given all these conclusions, we become confronted with the following question: does it make 
any sense to continue talking about linguistic nativism? In our opinion, we can answer this question affirmatively, providing that we partially revise the idea of innateness.

The crisis and the reflection on the concept of innateness are actually issues open to a very interesting debate among biologists and philosophers of biology. ${ }^{10}$ We should not be surprised by the necessity to think about its suitability in the field of linguistics, where it has been used for decades without so much reflection (see Cowie 1999). From our point of view, linguistics should shift its "input-output model" of innateness and embrace a "dispositional model", borrowing both categories from Stich (1975).

The former model (input-output model) strongly relies on the PS argument. It contains that the mismatch between, on the one hand, the scarcity and the imperfection of the information around children (input) and, on the other, the sophistication of the system of knowledge finally attained (output), leads to conjecture their being in possession of an important amount of information not derivable from experience and henceforth innate. For instance, data is presented to children in a strictly linear order, but they show early to be sensitive to a hierarchical organization underlying it. The most reasonable conclusion seems to be that the grammatical principles of hierarchical organization are known by children prior to any experience.

The second model (dispositional model) is based on the idea that an innate feature of a species is simply a property determined to appear at certain point of the developmental process of any member of it. An important aspect of this idea is that it treats innate features as phenotypical: what is innate, from this point of view, is the property and not the basis of its development. This implies, for instance, that a certain property of grammars can be considered innate in spite of not being the answer to a specific grammatical instruction from an innate base. In the case of the hierarchical mode of organization of linguistic utterances, the idea allows for two kinds of explanation:

1. It is a feature inherited from the external systems. Along these lines, Segal (1996), Cormack and Smith (2002) and Corballis (2002) locate its foundations on the compositionality of thought (even Fodor 1975: Ch. 3 can be so interpreted), while Calvin and Bickerton (2000) relate it with the planification and execution of motor gestures.

2. It is a feature somehow unavoidable for any combinatorial system, as held by Chomsky (1995a, 1995b), Berwick (1998) and StuddertKennedy and Goldstein (2003). 
In any event, the model views such a property as innate attending to its propensity to arise irrespective of the foundations of its development. ${ }^{11}$

It is easy to understand that there is no reason to abandon the thesis of innateness with the MP framed within the dispositional model of nativism. According to the MP, the ultimate foundations of the FL are certainly not linguistic, the interaction of the external systems during development being responsible for the emergence of a linguistic capacity and with genes perhaps only in charge of the development of those nonlinguistic systems. The growing of the FL is thus to be considered a side effect of the development of the external systems, which establish the conditions that, given a minimum amount of external stimuli, impel the implementation of a linguistic capacity as an aspect of the cognitive equipment of any individual. The FL is therefore an unavoidable result of certain initial nonlinguistic conditions and not the final outcome of an initial state of linguistic knowledge.

Summing up, linguistic nativism does not compel us to postulate a rich system of a priori linguistic knowledge somehow rooted in the genes. For the idea of innateness to be acceptable, it is enough to sustain that the genes establish certain phenotypical conditions from which the growing of a linguistic capacity becomes inescapable. ${ }^{12}$ Such a conception of linguistic nativism seems to us in complete agreement with the theoretical basis of the MP.

\section{The theory of language acquisition and the maximalist conception of human language}

Let us start by assuming the theoretically neutral idea that language consists of a cognitive procedure for the exteriorization of our thoughts and the internalization of other people's thoughts (for the sake of simplicity, we will use "exteriorization" as a term comprising both aspects of language use). "Exteriorization" and "thought" can be seen as two independent and autonomous activities, each one controlled from a specific cognitive system: the system of thought and the sensory-motor system, also known as the external systems when observed from the point of view of language (see Section 2.2 above). The system of thought provides us with the capacity of producing and maintaining intentional attitudes about the world (including our and other people's minds), while the sensory-motor system controls the workings of our auditive, visual, oral and gestural activities. From the point of view of the architecture of mind, language (FL) can be thought of as a bridging faculty, in that it provides the channel by which representations of the external systems 
become accessible to each other. Adopting this point of view, we can question whether or not the FL is a faculty in the very sense that the external systems (whose specificity is left out of question by the MP) are. In this respect, the linguist can endorse one of the following positions:

1. Maximalism. Language is a specific faculty of mind that imposes its own representational format (grammar) on thoughts in order to be translatable into psycho-motor instructions. According to this position, our mind contains an independent grammatical device, very rich and highly specific in its internal articulation and contents, which provides an interlingua between two systems otherwise mutually unreadable.

2. Minimalism. Thought is directly externalizable and the mind does not need to incorporate a specific grammatical system. This implies that the primitives and mechanisms of the FL are for the most part not different from the primitives and mechanisms of the external systems. Such an alternative does not leave aside the possibility that some unsystematic grammatical resources could be used in order to increase the efficiency of the FL, insofar as they do not constitute a representational vocabulary that forces an exhaustive process of format conversion. ${ }^{13}$

It is safe to affirm that the Government and Binding Theory (GB) developed in the 1980 s by generative grammarians exemplifies the clearest manifestation of a maximalist conception of human language (see Chomsky 1981, 1986, 1988), while the MP represents the evolution of the generative enterprise toward a minimalist understanding of language (see Chomsky 1995a, 1995b, 2000, 2001, 2002a, 2002b: Ch. 4, 2005). Notwithstanding, it is important to note that even if the affiliation to one or another of those conceptions is something we can evaluate in absolute terms, it is also true that we can measure the degree of maximalism or minimalism of a particular approach to a given phenomenon. Let us explain this point. Suppose we adhere to the minimalist position: in this case, our analysis of a particular linguistic fact could incorporate a certain amount of grammatical devices (i.e., elements uninterpretable by the external systems) and its degree of minimalism could vary according to the quantity of those devices. Anyway, our approach should qualify as minimalist as long as it observes the thesis that languages are optimal solutions to the legibility conditions imposed on them by the external systems and that they incorporate a minimal amount of machinery not readable by those systems (see Chomsky 2000: 96).

Something similar can be said about the maximalist conception of language. We can characterize as such any approach that ascribes the same 
cognitive specificity to the FL as to the external systems. However, the maximalism of a given study decreases if it imputes a certain prominence to the external systems over the FL: for instance, if our approach contends that the development of language is somehow instructed from the external systems. Let us think on the idea developed by Pinker (1989), according to which capturing phonological and semantic singularities could be the key to fixing the principles that constrain a given grammatical phenomenon. We can interpret this by supposing that the steady state of those principles is attained by resolving cues accessible by the external systems. This idea can be further interpreted in two different ways: on the one hand, those nongrammatical criteria could be understood as the triggers of a pre-existent but incomplete grammatical structure; on the other, the grammatical structure finally attained could be a not prefigured result in any blueprint. It is important to understand that such a position would not challenge either the innate character of the grammatical competence (see Section 2.3 above) or the maximalist affiliation of the approach, in that it would respect the basic condition of attributing to grammar a complete specificity from a cognitive point of view.

\subsection{The concept of the FL in acquisition theory: a brief introduction to the state of the art}

A summary of the situation we will describe in the following pages could read like this: while syntactic theory (henceforth, SynT) has directed its efforts to explore and to justify the strongest versions of the minimalist thesis from the beginnings of the nineties, acquisition theory (henceforth, AcqT) is still dominated by extreme versions of the maximalist position. Appearing as if a repellent force worked over both theoretical domains, the fruitful feedback between their results for more than thirty years seems to have been blown away with the arrival of the MP. Moreover, the situation is especially odd if we attend to the facts that (i) practitioners of each of these domains of inquiry seem not to be aware of it and that (ii) they usually declare their confidence in the existence of a community of interests between the fields, the need to pay attention to each other, and the acceptance of a sort of mutual control.

In order to present a preliminary view of the mismatch on the conception of the FL presumed by SynT and AcqT practitioners, we will start by focusing our attention on Thornton and Wexler (1999) and Guasti (2002), two works that can be considered to be illustrative of the state of the art in AcqT. What follows is a brief account of five basic assumptions normally taken for granted by acquisitionists, which actually open an 
insurmountable gap between their concept of the FL and that of syntacticians. In the next subsection (see 3.2) we will review a comprehensive sample of more specific articles corresponding to the period between 2001 and 2002 that basically confirm the findings of this preliminary account.

\subsubsection{Assumption 1: Universal Grammar (UG) as a richly articulated} $S_{0}$. Thornton and Wexler (1999: 1) contend that "a basic tenet of this theory [the theory of UG] is that much linguistic knowledge is part of the child's genetic makeup. This knowledge is encoded in the form of universal principles." Guasti (2002: 1) expresses herself with very similar words: "human beings are innately endowed with a system of richly structured linguistic knowledge." 14

We have explained in a previous section that one of the "basic tenets" of the MP is that the idea of a rich, detailed and specific structure of initial linguistic knowledge must be replaced by a conception in which the initial state must be (ideally) freed of any grammatical residue (see again Lorenzo and Longa 2003: Section 3). According to this conception, FL would be basically the result of the epigenetic processes triggered by the contact between the performance systems it is designed to bridge. Accordingly, FL would somehow lose its inherited character, but not (as previously explained) its congenital or innate nature.

\subsubsection{Assumption 2: the principles of $U G$ as domain specific. Both} Thornton and Wexler (1999) and Guasti (2002) assume that UG consists of principles exclusively in charge of the well-formedness of linguistic utterances. This means that they are only useful to a certain type of mental computations: those which have to do with the production and interpretation of sentences and other linguistic units. Guasti (2002: 8) points out, for instance, that principles of UG "prohibit certain arrangements of words, certain operations, and certain associations of sounds and meanings" and that sentences must conform to its requirements "if they are to be considered well formed or acceptable". Following the ideas put forward by Chomsky (as in 1986: 4 or 1988: 47), ${ }^{15}$ it seems clear not only that those tasks are completely entrusted in the principles of UG, but also that they have no other cognitive role (see on this the comments of Thornton and Wexler 1999: 1-2 and Guasti 2002: 404). ${ }^{16}$

The MP, on the contrary, tries to explain the principles that universally constrain the form of languages and of its products either as reflexes of the External Systems (interface conditions) or as bias towards the most simple solutions in domains not regimented by specific rules (virtual necessity conditions). ${ }^{17} \mathrm{FL}$ thus looses the autonomy that it has within maximalist models of language, in that most of its properties are those 
of other cognitive systems. ${ }^{18}$ Furthermore, it somehow becomes a "virtual" component of mind, in the sense that an important part of its principles does not need to be directly "printed" in the brain: it spontaneously follows given no other criteria established to the same effect.

\subsubsection{Assumption 3: a syntactocentric conception of mind and gram-} mar. "The principles of binding are often called constraints because they impose limits on the sentence forms and meanings that can be generated by the grammar. Constraints have assumed a central position in theories, such as Chomsky's theory of UG, that endow the child with innate knowledge of syntactic properties" (Thornton and Wexler 1999: 6). The content of this passage is directly applicable to any other domain of grammar as conceived of by the GB model put forward by Chomsky (1981) and subsequent works during the 1980s. The idea is basically that of Assumption 2 above, but it also implies that the modules of mind directly connected with FL must fit with the properties of grammar in order to fulfill their role in tasks related with the production and interpretation of utterances.

Things are considered to be the other way round by the MP: it is FL which is supposed to adjust to the formal properties of the systems it serves as a cognitive bridge. In other words, while according to the maximalist view it is the mind which must be adapted to its linguistic tool, according to the minimalist position it is language which accommodates and develops properties akin to those of other components of mind.

3.1.4. Assumption 4: a double hypothesis of modularity. The maximalist model of grammar developed by GB theory characterizes human language as "modular" in two different senses: on the one hand, FL is seen as one of the components (or "modules") in which the mind is articulated, each one being a specialized system from both an anatomical and a functional point of view (external modularity); on the other hand, FL itself is considered to be internally articulated in different subsystems (or "submodules"), each one devoted to a different aspect of the grammaticality of an utterance (internal modularity). From the point of view of external modularity, language is located at the same level of the analysis of mind as other components such as vision, face recognition, motor control, and so on. From the point of view of internal modularity, language is attributed a highly specific set of subsystems, such as phrase structure theory, thematic theory, case theory, binding theory, control theory and bounding theory. That this is the image of language assumed by Guasti can be confirmed by the following passage: "the comprehension of sentences including nominal and pronominal expressions results from the 
interaction of various components or modules: the lexicon, a syntactic binding component that prescribes the licit binding configurations, a semantic component that interprets syntactic binding [...]" (Guasti 2002: 284).

Differently, the MP relativizes, on the one hand, the condition of language as a distinct module of mind (see Fox 2000: 67-74) and, on the other, abandons the idea of its modular internal organization. Each of these ideas follows almost directly from the assumptions enumerated above, which imply a relaxation of the specificity of the FL, now seen as highly sensitive and receptive to the functional requirements of the external systems. As a consequence, the boundaries inter modules tend to disappear and those residual aspects of FL which still can be thought of as specific do not need to fall under particular components of grammar. ${ }^{19}$

\subsubsection{Assumption 5: a representational and multistratal architecture.} The maximalist conception of the FL contends that the system in charge of controlling the well-formedness of a linguistic utterance is organized as a set of successive strata or levels of representation (D-Structure $>$ SStructure $>$ Phonological Form / Logical Form). An utterance is understood as the result of a cyclic process of transformations and the levels are the "loci" at which some of the subsystems of grammar verify that the process is running according to the principles of UG.

The MP maintains, on the other hand, that the fulfillment of any condition that a linguistic expression must obey can be procrastinated until the point at which the "utterance-to-be" is submitted to the performance systems. Consequently, the notion of "level of representation" has no motivation within the minimalist model of the FL and grammar becomes a strictly derivational procedure (see on this Longa and Lorenzo 2001: Ch. 4). The architecture of the FL is basically reduced to a minimal distinction between a lexicon and a computational system. Expressions are legitimate as far as they are legible by the external systems and they are not checked at any point of the derivational process. The steps of a derivation are conducted by principles of extreme simplicity and no specific principles of grammar control their outcomes. ${ }^{20}$

The five assumptions enumerated up to this point are surely enough to understand the magnitude of the theoretical gap remaining open between the maximalist and the minimalist conceptions of the FL and, accordingly, between AcqT and SynT, whose practitioners seem respectively inclined to the former and the latter image of human language, as we will try to show in detail in the following subsections. But maybe Chomsky's own words introducing the MP are the most effective means of expressing such a breach: 
There is no Deep or Surface Structure, or other levels that have been proposed. It holds that everything accounted for in these terms has been misdescribed and is better understood in terms of legibility conditions at the interface: that includes the Projection Principle, Binding Theory, Case Theory, the Chain Condition, and so on. [...]. There should be no government, no stipulated properties of chains, no binding relations internal to language, no interactions of other kinds [...], no phrasal categories or bar levels, hence no X-bar theory or other theory of phrase structure apart from bare phrase structure. (Chomsky 2000: 113)

Furthermore, he concludes that "a basic assumption of the work in the Principles and Parameters framework [specifically, the GB model], with its impressive achievements, is that everything just suggested is false: that language is highly «imperfect» in these respects" (Chomsky 2000: 113). But what happens to be false to Chomsky is, after all, that the FL is a highly specific and autonomous component of mind, with a rich internal articulation, whose contents have no justification outside their grammatical commitments.

The situation we are pointing at, and that we will try to illustrate at large in the pages to follow, is that AcqT and SynT embrace images of the FL not only conceptually in conflict but also mutually exclusive from an empirical point of view. Contrary to certain statements, those images do not simply respond to notational variants for the same phenomena (as held by Rizzi 2000: 284, who says that bare phrase structure is but a "more rudimentary structural schemata" of $X^{\prime}$ Theory): actually, the truth of one implies the falsity of the other. Nor are they different states in a single line of conceptual evolution towards simplicity under otherwise identical theoretical premises (as Friedemann and Rizzi 2000: 3 and Valois 2000: 3 contend). ${ }^{21}$ The gap is a theoretically real and insurmountable one. In the present situation, thus, neither AcqT can be thought of as an experimental field for SynT nor SynT as a "think tank" for AcqT.

\subsection{An analysis of the concept of FL in a selection of recent articles on language acquisition}

The previous section has offered the background of the theoretical mismatch between SynT and AcqT within the generative approach to human language: while the former is devoted to hammering out the strongest minimalist thesis from more than a decade, the latter still moves within extreme versions of the maximalist conception of the FL. Such a breakdown of a formerly unified enterprise towards the explanation of the nature of language is even more surprising if one notices the seeming lack of awareness on both sides of the fields. In this subsection we will show the 
liveliness of the main maximalist assumptions about the FL in a representative sample of articles on acquisition published during the years 2001 and 2002 in the most diversified and prestigious journals on linguistic theory and language acquisition. ${ }^{22}$ The review is organized as follows: firstly, we will show the main theoretical lines shared by those articles relative to the five assumptions established in the previous subsection (Section 3.2.1); secondly, we will minutely examine a group of articles that adheres to certain minimalist ideas while at the same time showing a general maximalist view on language (Section 3.2.2); finally, we will comment on the few articles that exhibit either a minimalist or, at least, a weak maximalist view on the FL (Section 3.3.3).

\subsubsection{Main theoretical trends}

- Assumption 1: Universal Grammar (UG) as a richly articulated $S_{0}$ The MP aims to eliminate any piece of grammatical machinery (principles, conditions, rules, and so on) from UG, reinterpreting the notion of $S_{0}$ as a function of the development and contact of the performance systems. Accordingly, the FL should be made of primitives coming from those systems and should be ruled by criteria also inherited from them or motivated by laws of necessity or simplicity. In a way, the very notion of UG, understood as an inborn structure of domain specific knowledge, loses almost all of its original motivation within the minimalist framework. However, most of the articles from our sample continue to rely upon a maximalist notion of UG, ${ }^{23}$ seen as the child's innate knowledge of language (Goodluck et al. 2001: 159, Babyonyshev et al. 2001: 1-2, Thornton 2002: 258), as a domain specific array of grammatical knowledge (Santelmann et al. 2002: 818, 838), or as the basic blueprint of language (Hyams 2002: 229). Altogether, they leave us with an image of UG as a rich structure of grammatical knowledge, i.e., unmotivated from the point of view of other cognitive domains, as will be confirmed in the following point.

- Assumption 2: the principles of UG as domain specific

Matsuo and Duffield (2001: 306) base their analysis of gapping constructions in English on very "specific syntactic constraints", 24 while Santelmann et al. (2002: 838) speak of "fundamental syntactic principles". McKee and McDaniel $(2001: 114,115,118)$ articulate their analysis of extraction of resumptive pronouns according to highly specific grammatical principles and Drozd (2001: 97) analyzes the behavior of negative DPs in a very similar vein. Goodluck et al. (2001: 169) point out the possibility of certain aspects of early 
grammars being controlled by semantic (i.e., intentional and conceptual) criteria, but conclude that in the steady state finally attained those very aspects become controlled by specifically grammatical principles. Babyonyshev et al. (2001) work with the idea of a pre-existent set of grammatical principles open to a maturation process and, not surprisingly, they follow Chomsky (1981)'s analysis of passive constructions. ${ }^{25}$ Hyams (2002) and Petinou and Terzi (2002) assume a full-fledged functional structure with uninterpretable heads, and the latter also assume the $\mathrm{X}^{\prime}$ vocabulary, a typical illustration of a violation of Chomsky's (1995b) Principle of Inclusiveness. ${ }^{26}$ Tracy (2002: 656) observes that many crucial notions of her analysis (such as "head", "agreement", "scope" or "binding") "do not arise in other cognitive domains". The situation so far described contrasts heavily with the minimalist ideas in favor of the functional indefinition (or generality) and the functional subordination (to the performance systems) of the vocabulary and principles of the FL.

- Assumption 3: a syntactocentric conception of mind and grammar Most of the articles under scrutiny embrace without criticism a selfcontained and autonomous concept of grammar. Crago and Allen (2001) employ a theory based on the [ \pm interpretable] character of the [D] feature, but with no comment at all about the systems of thought which are supposed to be the foundations of such a distinction. Santelmann et al. (2002: 815) recognize that semantic and pragmatic factors are certainly relevant in the acquisition of question formation, but they focus on the problems raised by inversion in child grammar without dealing with those factors. McKee and McDaniel (2001: 115) analyze the extraction of resumptive pronouns in child grammar by means of principles that make no reference to the exigencies of the interfaces. Goodluck (2001) approaches the analysis of adjunct PRO clauses under the assumption that the child operates with them without the help of her knowledge of the lexicon of the language. ${ }^{27}$ Hyams (2002) also dissociates grammatical and lexical knowledge when explaining the projection of functional categories. Borer and Rohrbacher (2002: 132-133) adopt a "top down" model in which syntax "determines the choice of words". It is very clear in all these articles that syntax is at the core of all the workings of language and, crucially, of the process of language acquisition.

- Assumption 4: a double hypothesis of modularity

Babyonyshev et al. (2001) adopt Chomsky's (1981) analysis of passive constructions and Goodluck (2001) bases her analysis of PRO 
and nominal constructions on Jaeggli (1986). Both Chomsky (1981) and Jaeggli (1986) work with principles coming from different modules of grammar (theta theory, case theory, and so on). McKee and McDaniel (2002: 149) contend that the acknowledgment of the contributions of the performance systems in the developmental processes does not imply "sacrificing modularity (in the architecture of language and cognition and in the different linguistic systems)". Santelmann et al. (2002) dissociate the analysis of inversion from the analysis of any other concurrent factor (type of verb, modality, and so on) of a question. In all the cases, the result is a strongly compartmentalized and very sophisticated image of grammar.

- Assumption 5: a representational and multistratal architecture Contrary to the previous assumptions, this one is almost absent from the articles of our sample. Most of the articles adopt the idea of a "spell-out" point at which the derivation divides into two parallel processes (PF and LF), with conditions applying at the interfaces of those parallel derivations with the performance systems. Only Babyonyshev et al. (2001), Goodluck (2001) and Matsuo and Duffield (2001) continue to apply filters of grammar at certain specific points of the derivation.

\subsubsection{Mixtures of maximalist and minimalist contentions: a brief analy-} sis. Some of the articles under scrutiny, while adopting a clearly maximalist conception of language, incorporate certain theoretical elements of the MP within their analytical depot. In this respect, it is important to note two different things:

1. that the image of FL that serves as the theoretical background for these articles is not a very congruous one; and

2. that in most cases those minimalist notions are not the ones that the articles are trying to test from the point of view of language acquisition.

Let us start by commenting on Wexler (1999), a very illustrative piece of work in this sense (in spite of being outside of our chronological scope). Wexler (1999: 78-79) suggests that certain aspects of linguistic maturation are a function of prior maturation and coordination of the interface levels. This clearly sounds like a minimalist assumption: some elements of the computational system of grammar are settled from the performance systems (system of thought and sensory-motor system). Wexler devotes himself to the analysis of certain phenomena concerning relationships between the computational system and the system of thought; we will concentrate ourselves on his analysis on the acquisition of finiteness. 
Wexler starts by observing that during the "optional infinitive stage", Tense is optional in the grammar of children acquiring a "non-prodrop" language. His explanation to this fact is that the child does not know whether the D feature is or is not an interpretable one (in adult grammar this feature is always [+interpretable]). When the child takes D as an interpretable feature, she produces sentences resembling those of adults; when the child takes the feature as an uninterpretable one, she omits Tense, thus preventing D from being checked twice (against Tense and against AgrS). Wexler (1999: 100) contends that if the hypothesis proves to be true, then it is possible to assert that children have a complete knowledge of the functioning of the Computational System and that they only need to fix their knowledge concerning the interpretative status of features, obviously dependant on their role in performance.

Wexler's article thus concedes a central role to the external systems in the development of FL, very much in the spirit of minimalism. However, his general framework is far from being a really minimalist one: he contends that the Computational System is an autonomous module of mind, its functioning being governed by very specific principles and its development consisting in the growing of a scheme which is unmotivated from the point of view of the external systems. On his view, the development of language is to be related with an explicit genetic program (see Wexler 1999: 56-58, 69, 74, and 77) more than with the development of the external systems.

Borer and Rohrbacher's (2002) article includes many minimalist ideas, such as the centrality of checking theory. However, they contend that syntax is in charge of the selection of words, thus embracing a syntactocentric model of the FL unfamiliar to the main trends of the MP. Crago and Allen (2001) focus their attention on the optional infinitive stage in the development of Inuktitut grammar, adopting Wexler's (1998) key ideas and his (1999) analysis. In spite of the central role of the [ \pm interpretable] status of features within this framework, the fact that nothing is said about the foundations of such a distinction is very revealing.

Hyams (2002) defends a strong continuity between the child grammar and the adult grammar of Greek speakers. She assumes many elements of the MP in her analysis, such as checking theory, a phrase structure component based on the operation Merge, and so on. She even claims that her article gives additional support to Chomsky's idea concerning the primacy of Merge over Move/Attract (Chomsky 2000; see Hyams 2002: 258). However, the main ideas that the article is devoted to testing are not of a minimalist affiliation: i.e., that the functional structure of sentences is part of the basic blueprint of language (Hyams 2002: 229), and 
that UG consists of a set of universal grammatical principles (p. 263). Furthermore, the article dissociates lexical and grammatical knowledge very strongly and it holds that the child has a very complete syntactic competence even prior to being capable of putting it to use by the insertion of complete paradigms (p. 231). It is also clear that Hyams understands that syntax is the way for children to discover the interpretative subtleties of adult grammar (p. 234), and not the other way round.

McKee and McDaniel (2001) also adhere to many ideas of the MP. For instance, they take resumptive pronouns to be the spell-out of traces, pronounced when the traces themselves are not legitimate given certain economy-based constraints governing derivations (p. 113). Nevertheless, they insist on the specifically syntactic nature of the principles constraining extraction operations (p. 114-115) and they make no reference at all to the interfaces and their constraining role upon syntax. ${ }^{28}$ Petinou and Terzi's (2002) analysis of clitic misplacement in a variant of Greek follows certain minimalist ideas, such as checking theory, while retaining many elements of the maximalist approach, such as the $\mathrm{X}^{\prime}$ theory in the analysis of phrase structure. ${ }^{29}$ In a similar vein, Santelmann et al. (2002) ground their analysis of inversion on Chomsky (1995b), but they adopt a strong domain-specific and syntactocentric conception of FL. Moreover, they do not explore the role of the external systems in the development of inversion, despite the significance of the interpretable feature [Wh] in their analysis. ${ }^{30}$

As a last illustration, Tracy (2002) defends the idea that children make use of three different resources when discovering the abstract properties of grammars: (i) a six domain-specific principled UG; (ii) certain general cognitive strategies; and (iii) a mechanism in charge of inferring the existence and the position of heads and thus establishing the linking between UG and the input (HEad DeteCTOR or Hector). Components (i) and (ii) represent an evident interplay of maximalist and minimalist means in order to reach the goal of acquiring the grammar of a given language. But perhaps more curious than this is Tracy's contention that by applying the Hector children somehow can be said to be holding the presumption of a perfect design underlying the input, in the spirit of Chomsky (2001). The idea sounds rather weird if one notices that the Hector is ancillary to the $\mathrm{X}^{\prime}$ scheme (an imperfect device, in Chomsky's view) and that UG (in Tracy's framework) contains six domain-specific (and hence imperfect) principles. We should once more remember that the minimalist notion of "perfection" has nothing to do with the matching of certain a priori grammatical knowledge with the input, but rather with the possibility of deriving any piece of our knowledge about language either from the external systems or from principles of a very general and unspecific nature. 
3.2.3. Non-strongly maximalist articles: a brief analysis. Only two of the articles so far considered can be labeled as non-strongly maximalist: Jordens (2002), which embraces a weak version of maximalism, and Gavruseva and Thornton (2001), a piece of work which can be classified as strongly minimalist.

Jordens (2002), a study on the acquisition of finiteness in Dutch, defends the idea that this grammatical feature does not exist in the earliest states of grammar, which means that it has to be acquired by children. The author proposes a developmental process crossing three stages, each one with an increasing degree of grammatical specialization. Namely, in stage one (or holistic stage) finiteness is expressed by means of holistic modal operators, while in stage two (or conceptual-ordering stage) a series of proto-functional items are acquired in order to express illocutionary force. In this second stage, utterances consist of three structural positions, each one showing a certain discursive specialization: topic (first position), illocutionary force (second position) and information concerning the topic (third position). These positions are syntactically related by adjunction, with a lineal ordering based on information processing criteria. In stage three (or "finite-linking" stage), the proto-functional category in charge of the expression of illocutionary force gets reinterpreted by means of the functional category AUX as a side effect of the acquisition of auxiliary verbs. Moreover, the simultaneous emergence of auxiliaries and pronouns related with the external argument triggers the agreement relation between AUX and the argument. In this stage adjunction is also replaced by a properly hierarchical structure, with AUX adopting the role of head. To sum up, Jordens contends that acquiring finiteness implies a developmental process crossing a pragmatic stage, a lexical stage, and a properly grammatical stage, each one representing the adoption of an increasing degree of grammatical machinery.

We judge Jordens' article as weakly maximalist attending to the role attributed to the performance systems (namely, the system of thought) in the developmental process leading to the acquisition of a certain aspect of grammar. However, we are refrained from designating it as minimalist (even weakly minimalist) by the fact that the process leads to a selfcontained and highly specific grammatical system.

Gavruseva and Thornton (2001) study the acquisition of whosequestions in order to elucidate whether the child "knows" that the whole whose-phrase undergoes obligatory pied-piping. They focus their attention on children that produce segmented whose-questions, i.e., with (sub)extraction of the wh-possessor (such as "who do you think's flower fell off?"). They contend that such segmented questions are not due to the deficient setting of a parameter, but to the application of a natural 
economy principle that delays the application of the PF filter that requires the pied-piping of certain entire phrases. The authors work with natural economy or virtual necessity conditions inspired by Chomsky (1995a, 1995b) and they claim that such conditions govern both the language acquisition device and the computational system, competing with other conditions projected from the performance systems. The resulting picture is therefore very much on the spirit of the MP.

\section{Concluding remarks}

It is our opinion that this article illustrates at large the current divorce between SynT and AcqT within the generative framework. On the one hand, SynT has withdrawn acquisition matters from the criteria governing the explanatory adequacy of theoretical proposals; AcqT, on the other hand, seems to accept neither the redefinition of innateness nor the concept of the FL provided by SynT. It is clear that AcqT has stopped being applied to validating the results of SynT, but it is also clear that acquisitionists do not seem to understand (or at least not explicitly) that the results of their own research programs are somehow questioning some of the speculations held by minimalist syntacticians. The situation is even more confusing given the fact that many acquisitionists declare themselves followers of the MP, usually against the premises and conclusions of their own work. ${ }^{31} \mathrm{We}$ cannot predict the future developments of the situation, but we would like to conclude our article by proposing two points of clarification that the field urgently needs:

1. The development of a really minimalist research program in language acquisition would be very important. The results of such a program would be of enormous interest. Moreover, even if the MP does not acknowledge the metatheoretical role that generative grammar used to assign to AcqT, it is however out of question that acquisition continue to be an experimental field of primary interest for theoretical linguistics of any orientation.

From our point of view, in order to make the MP its own framework, AcqT should urgently take into account capacities that are not linguistic by nature (or not specifically linguistic), either related to the conceptualization of the environment or to the performance of motor plans, in order to verify the possibility that there AcqT will find the key to explaining the main design features of grammar and its development in the child's mind (unspecificity of the computational procedures, tendency towards the simplest or most 
economic procedures, etc.). Another recommendation that any theory based on minimalist premises should urgently accept is to avoid any kind of grammatical imperfections (uninterpretable categories, elements introduced during the computation and levels of representation that are unconnected to the external systems), at least as the starting hypothesis about the initial state of the FL. A minimalist theory on acquisition should be ultimately based on the strongest approximation possible to the "bare conditions" imposed by the external systems as optimal descriptions (even though "amendable") that might be attributed to the $\mathrm{S}_{0}$ of FL, thus satisfying Chomsky's assumptions concerning a true "principled" explanation of the properties of language: "We can regard an explanation of properties of language as principled insofar as it can be reduced to properties of the interface systems and general considerations of computational efficiency and the like" (Chomsky 2005: 10).

2. Work on language acquisition with a nonminimalist alignment should make explicit its maximalist premises and present itself as critical and capable of questioning the contentions of the MP. Some comments about this point are in order. One of the reviewers of this article has pointed out to us that "Chomsky [...] did not create [the MP] to account for how children acquire language", which, in his opinion, frees those who study acquisition from the need to adopt the theoretical principles of this frame ("I do not see why generative acquisitionists should use machinery developed in the MP"). We acknowledge that his first assertion is absolutely correct, but we think that the conclusion that the reviewer reaches from that assertion is much more doubtful.

As far as the first point of the question is concerned, we indeed sustain that in the MP framework the acquisition of the native language stops granting explanatory criteria to the theory of grammar, which is now assumed by the "strongest minimalist thesis", according to which a theory of grammar is the more explanatorily adequate the more it assumes an adjustment between the functioning of the external systems and that of grammar itself (see, however, Eguren and Fernández Lagunilla [2004: 216], who expose a point of view that is contrary to ours). But this does not mean that acquisition has lost any interest to the theory of grammar: the fact that Chomsky declares it to be "irrelevant in principle" implies only that the learning perspective must not condition the departure point of the theoretical formulations, but does not imply that it cannot be conceded "relevance a posteriori" as an additional element of corroboration. 
As regards the second point, it is unquestionable that any type of experimental research must take as a point of departure a certain theoretical model about the object that will be studied, and the research of language acquisition cannot be an exception. The FL model suggested by the MP is, in principle, as good as any other to face this kind of research, regardless of the degree of attention that acquisitionists may receive to the results of their work. There is nothing that prevents acquisitionists from adopting the model of grammar suggested by the MP as appropriate to account for the way children acquire language and also from aspiring to their experimental conclusions being acknowledged as a further factor of correction or even of disapproval of such a model. Besides, there is obviously nothing that prevents acquisitionists from adopting a maximalist model of grammar as well. Nevertheless, if that should be so, they must assume that they work against the mainstream of basic research and that, at most, their conclusions should be better presented as corrections rather than as validations of the most recent developments of the generative framework.

Received 1 March 2005

Revised version received

8 July 2005
University of Santiago de Compostela University of Oviedo

\section{Notes}

* This research was funded by the Spanish Ministry of Education and Science and FEDER under the project "Biolinguistics: genetic foundations, development, and evolution of language" (HUM2007-60427/FILO). We wish to express our gratitude to Neil Smith and two anonymous Linguistics reviewers for their thoughtful suggestions and to Martha Crago, Nigel Duffield, Elena Gavruseva, Cecile McKee and William Snyder for providing us with copies of some articles that we could not have consulted otherwise. Last, but not least, we also wish to thank Iris Pereira for her support and comments on an earlier version of this article. Correspondence address: Víctor M. Longa, University of Santiago de Compostela, Praza Isabel A Católica, 36204 Vigo (SPAIN). E-mail: fevlonga@usc.es.

1. See Thomas (2002) for an historical approach. We disagree with this author in that Chomsky (1959) seems to us to point to the argument much more than she is inclined to accept.

2. A significant reference in this context is Hoekstra and Kooij (1988: 45). They claim that the postulation of linguistic universals is only a derivative aim of the theory in that it must be subordinated to the main goal of explaining the uniformity of language acquisition in spite of a "varied, degenerate, random and nonstructured experience". This is also a recurrent theme in Lightfoot's works. See Lightfoot (1999) and Anderson and Lightfoot (2002). 
This should not be interpreted to mean that other arguments concerning the characterization of language as an innate faculty (like those having to do with uniformitarianism, heritability of language impairments, etc.) are not relevant within the context of an "in depth" reconsideration of the thesis. However, we will focus here on the PS argument, taking into account (1) that it is the argument most closely related to learnability matters and (2) that in Section 3 we shall comment only on articles on first language acquisition and not on language universals or language impairments.

3. This section was written after the publication of the monographic issue of The Linguistic Review (2002) 19 (1-2) on the Poverty of Stimulus Argument. We will focus our discussion on the ideas expressed in this issue, sometimes ignoring previous debates on the matter.

4. Hornstein and Lightfoot (1981:9-10) had already suggested that the deficiencies attributed to linguistic stimuli are of three kinds, namely those summarized by Thomas.

5. To present innateness as a "novel and surprising proposition" is only possible if one forgets (or simply ignores) the historical philosophical (Plato, Descartes or Leibniz), psychological (Huarte de San Juan) and even linguistic (von Humboldt) antecedents of the idea.

6. In close relation with this, Fodor and Crowther (2002: 115, [our emphasis]) point out that "children may be exposed to a linguistic construction shortly before first uttering it EVEN IF EXPOSURE TO IT IS NOT NECESSARY FOR KNOWING IT AND USING IT CORRECTLY".

7. A more recent but identical claim can be found, for instance, in Crain (1991: 597): "a fundamental goal of linguistic theory is to explain how natural languages are acquired".

8. In Chomsky's (2000: 96) own words: "Suppose that FL satisfying legibility conditions in an optimal way satisfies all other empirical conditions too: acquisition, processing, neurology, language change, and so on. Then the language organ is a perfect solution to minimal design specifications. [...] The Minimalist Program explores the possibility that language approaches "good design" in this sense. The strongest minimalist thesis would be this: "Language is an optimal solution to legibility conditions". Insofar as the thesis is true, information about other matters (sound-meaning connections, neurophysiology, etc.) [also acquisition; see above] may be helpful in practice - even indispensable - for discovering the nature of FL and its states. But it is irrelevant in principle".

9. Perhaps with a residual and nonstructured amount of grammatical or noninterpretable features (case, agreement, etc.). See Chomsky (2000: Section 3.5).

10. See the monographic issue of The Monist on the "Philosophy of Biology", which contains two very important articles on innateness: Griffiths (2002) and Maclaurin (2002).

11. Along these lines, Maclaurin (2002: 126) claims that "all I require for the existence of an innate trait is that there exist within the population some mechanism or process that maintains the developmental resources which very reliably produce the trait in question". The idea does not prejudge anything about the specific mechanism of development, in that "it must accept traits that are built into populations by a variety of different mechanisms and it must accept traits that are built into populations by a variety of ways" (Maclaurin 2002: 109).

12. Thus in agreement with the concept of epigenesis as defined by Futuyma (1998: 651): "the processes that intervene during the development of an organism (its ontogeny) between primary gene action and the phenotypic traits". See Lorenzo and Longa (2003: 652-653) on the application of the idea to the goals of the MP.

13. It is interesting to note that Newmeyer (1998: 27-32) considers "systematicity" as the key feature of an autonomous and specific grammatical component of mind. It 
is this feature, in our opinion, that is most left aside by a minimalist conception of language.

14. See, along the same lines, Anderson and Lightfoot (2002), Crain and Pietroski (2001), Crain and Lillo-Martin (1999), Friedemann and Rizzi (2000), Lust (1999), Valois (2000) and Wexler (1999), among many others.

15. Chomsky asserts there that FL has "specific structure and properties" (1986: 4) and that it incorporates "quite specific principles" (1988: 47).

16. In Crain and Wexler's (1999: 388) words: "language apparatus [...] operates according to principles that are specific to it and not shared by other cognitive systems".

17. See Lorenzo (2001: Ch. 4).

18. As Chomsky (2005: 9) puts it, "we need no longer assume that the means of generating structured expressions are highly articulated and specific to language. We can seriously entertain the possibility that they might be reducible to language-independent principles".

19. According to the maximalist conception, the faculty of language is a highly specific system of knowledge; according to the minimalist conception, it is more like an "intermodular" transfer system. Using Samuels' (2000) terminology, the transition from the former conception to the latter is essentially a transition from a "Chomskyan module" (Grammar, in the GB style) to a "Darwinian module" (the Faculty of Language "in the narrow sense" - FLN - of Hauser, Chomsky and Fitch 2002).

20. The elimination of any level of representation (such as S-Structure) or of any representational vocabulary (such as c-command) can be seen as an aspect of the "strongest minimalist thesis" under the assumption that derivations and derivational vocabulary (such as Merge) are still needed. Brody (2002) contends that the opposite can also be defended and he argues in favor of a radical representationalist approach to syntax (see Brody 1995 and further works). The idea is, however, infrequent within generative theorizing, as Brody himself recognizes (see Brody 2002: 19). We therefore choose to ignore it in this article.

21. The following passage from Thornton and Wexler (1999: 4-5) could serve to illustrate this attitude: "The technical implementation of the binding theory has changed as the theory of generative grammar has evolved, and it is still in flux as the Minimalist Program is being developed (Chomsky 1995) [...]. The exact implementation of the principles is not crucial to us, however. What is crucial is that the binding theory, however formulated, is part of the language apparatus and, presumably, part of children's innate knowledge".

22. The criterion at work for our search and further analysis was to select generative articles dealing with the acquisition of syntactic (and/or syntactic-semantic) aspects in normal (nonimpaired) children. According to such criteria, we have selected the following 16 articles: Babyonyshev, Ganger, Pesetsky, and Wexler (2001), Borer and Rohrbacher (2002), Crago and Allen (2001), Drozd (2002), Gavruseva and Thornton (2001), Goodluck (2001), Goodluck, Terzi, and Chocano Díaz (2001), Hyams (2001), Jordens (2002), Matsuo and Duffield (2001), McKee and McDaniel (2001), Petinou and Terzi (2002), Santelmann, Berk, Austin, Somashekar, and Lust (2002), Snyder, Senghas, and Inman (2001), Thornton (2002) and Tracy (2002). They come from the following journals: Canadian Journal of Linguistics, Journal of Child Language, Journal of Linguistics, Language, Language Acquisition, Lingua, Linguistic Inquiry, Linguistics, Linguistics and Philosophy, Natural Language and Linguistic Theory, The Linguistic Review, and Theoretical Linguistics. It should be noted, though, that the situation remains unchanged as regards papers presented at conferences. For instance, the 
Proceedings of the 26th (November 2001) and 27th (November 2002) Boston University Conference on Language Development (see respectively Skarabela, Fish, and Do 2002; Beachley, Brown and Conlin 2003) contain more than 30 articles that meet our requirement. However, only 3 of them adopt (fully or partially) a framework based on minimalist assumptions.

23. Actually, all of them, with the exception of Jordens (2002) and Gavruseva and Thornton (2001).

24. For a minimalist approach of ellipsis and related phenomena (antecedent contained deletion, verb phrase ellipsis, pseudogapping,), see Lasnik (1999a: Ch. 3, 5, 7).

25. Consequently, their analysis of A-chains fully assumes a GB framework. See Lasnik (1999b) and specially Bobaljik (2002) for a minimalist approach to such chains.

26. On this issue, see Chomsky (1995a) and Collins (2002). An anonymous Linguistics reviewer correctly observes that some research of unequivocal minimalist affiliation continues to use the $\mathrm{X}^{\prime}$ scheme as the model of phrase structure and he points out Lasnik (1999c) as a standard example. In fact, it is a relevant case and worth commenting on, since in his article he adds the use of uninterpretable functional categories (AgrS, AgrO, against the Principle of Full Interpretation) to the inclusion of objects that are due to the $\mathrm{X}^{\prime}$ scheme (against the Principle of Inclusiveness). And, even if the use of $\mathrm{X}^{\prime}$ metalanguage in an article as the one we are commenting on may be considered uncontroversial, since it is used only as a convenient notational system, the point concerns the projection of the aforementioned functional categories and the crucial role they play in the analysis. Does this mean that the work done by Lasnik should better be classified as "nonminimalist"? Certainly not. We must not forget that minimalist theory takes principles as "inclusiviness" or "full interpretation" as points of departure and introduces "corrections" (for example, levels of projection or uninterpretable categories; that is to say, "imperfections") Only by doing so we can reduce the data to a better explanation. We can, therefore, see Lasnik's heads and uninterpretable projections as "partial corrections" of the initial assumptions of the research program, which he, apart from that, accepts. However, those aspects that we have discussed above in the acquisition literature are prone to a considerably different analysis, because in such cases the "imperfections" do not result from the demands required by the explanation, but are part of the initial assumptions. In that way, the motivation of the authors is evidently "nonminimalist".

27. O'Neill (1997), Cormack and Smith (2002) and Hornstein (2001: Ch. 2) deserve careful consideration regarding their minimalist treatment of PRO phenomena.

28. See Boeckx (2003) and McCloskey (2002) for a minimalist approach to resumptive pronouns and related phenomena.

29. See Boskovic (2001) and Panagiotidis (2002) as examples of studies approaching clitics from a minimalist perspective.

30. See Chomsky (1995b: 289ff.) and Bailyn (2004).

31. Even though in our article we have observed a tendency toward superficial invocation of assumptions and notions of the MP, which is not followed up by an effort truly intended to validate them, we should also recognize that this does not always happen. Jordens (2002), to which one of the reviewers calls our attention, is perhaps the most outstanding example. Jordens' research has an obvious generativist orientation, even though showing a certain onset neutrality regarding the "minimalist/maximalist debate", because the use of notions such as functional category, adjunction or AUX, as basic elements of the syntactic analysis, does not force this researcher to take sides in this question. Our consideration of this research as "weakly minimalist" does not refer to any position that has been declared by the author, but to the pattern he adopts in his 
explanation of the concrete fact of language acquisition that he studies, which is grounded in considerations of "conceptual-intentional" order.

\section{References}

Anderson, Stephen R. and Lightfoot, David (2002). The Language Organ: Linguistics as Cognitive Physiology. Cambridge: Cambridge University Press.

Babyonyshev, Maria; Ganger, Jennifer; Pesetsky, David; and Wexler, Kenneth (2001). The maturation of grammatical principles: evidence from Russian unaccusatives. Linguistic Inquiry 32(1), 1-44.

Bailyn, John Frederick (2004). Generalized inversion. Natural Language and Linguistic Theory 22(1), 1-50.

Beachley, Barbara; Brown, Amanda; and Conlin, Frances (eds.) (2003). Proceedings of the 27th Annual Boston University Conference on Language Development, 2 vols. Somerville, MA: Cascadilla Press.

Berwick, Robert C. (1998). Language evolution and the Minimalist Program: the origins of syntax. In Approaches to the Evolution of Language: Social and Cognitive Bases, James Hurford, Michael Studdert-Kennedy, and Chris Knight (eds.), 320-340. Cambridge: Cambridge University Press.

Bobaljik, Jonathan (2002). A-Chains at the PF-interface: copies and "covert" movement. Natural Language and Linguistic Theory 20(2), 197-267.

Boeckx, Cedric (2003). Island and Chains: Resumption and Stranding. Amsterdam and Philadelphia: John Benjamins.

Borer, Hagit and Rohrbacher, Bernhard (2002). Minding the absent: arguments for the full competence hypothesis. Language Acquisition 10(2), 123-175.

Boskovic, Zeljko (2001). On the Nature of the Syntax-Phonology Interface: Cliticization and Related Phenomena. Amsterdam and London: Elsevier.

Brody, Michael (1995). Lexico-Logical Form: A Radically Minimalist Theory. Cambridge, MA: MIT Press.

- (2002). On the status of representations and derivations. In Derivation and Explanation in the Minimalist Program, Samuel D. Epstein and T. Daniel Seely (eds.), 19-41. Oxford: Blackwell.

Calvin, William H. and Bickerton, Derek (2000). Lingua Ex Machina. Reconciling Darwin and Chomsky with the Human Brain. Cambridge, MA: MIT Press.

Chomsky, Noam (1959). Review of Skinner's Verbal Behavior. Language 35(1), $26-58$.

- (1965). Aspects of the Theory of Syntax. Cambridge, MA: MIT Press.

- (1980). Rules and Representations. New York: Columbia University Press.

- (1981). Lectures on Government and Binding. Dordrecht: Foris.

-(1986). Knowledge of Language: Its Nature, Origins, and Use. New York: Praeger.

- (1988). Language and Problems of Knowledge. Cambridge, MA: MIT Press.

-(1995a). Bare phrase structure. In Government and Binding Theory and the Minimalist Program, Gert Webelhuth (ed.), 383-439. Oxford: Blackwell.

-(1995b). The Minimalist Program. Cambridge, MA: MIT Press.

- (2000). Minimalist inquiries: the framework. In Step by Step: Essays on Minimalist Syntax in Honor of Howard Lasnik, Robert Martin, David Michaels and Juan Uriagereka (eds.), 89-155. Cambridge, MA: MIT Press.

-(2001). Derivation by phase. In Ken Hale: A Life in Language, Michael Kenstowicz (ed.), 1-52. Cambridge, MA: MIT Press. 
-(2002a). Beyond explanatory adequacy. MIT Occasional Papers in Linguistics 19. Cambridge, MA: MIT Press.

- (2002b). On Nature and Language. Adriana Belletti and Luigi Rizzi (eds.) Cambridge: Cambridge University Press.

- (2005). Three factors in language design. Linguistic Inquiry 36(1), 1-22.

Collins, Chris (2002). Eliminating labels. In Derivation and Explanation in the Minimalist Program, Samuel D. Epstein and T. Daniel Seely (eds.), 42-64. Oxford: Blackwell.

Corballis, Michael C. (2002). From Hand to Mouth: The Origins of Language. Princeton: Princeton University Press.

Cormack, Annabel and Smith, Neil (2002). Compositionality, copy theory, and control. University College London Working Papers in Linguistics 14, 355-375.

Cowie, Fiona (1999). What's Within: Nativism Reconsidered. New York: Oxford University Press.

Crago, Martha B. and Allen, Shanley E. M. (2001). Early finiteness in Inuktitut: the role of language structure and input. Language Acquisition 9(1), 59-111.

Crain, Stephen (1991). Language acquisition in the absence of experience. Behavioral and Brain Sciences 14, 597-612.

Crain, Stephen; and Lillo-Martin, Diane (1999). Introduction to Linguistic Theory and Language Acquisition. Oxford: Blackwell.

Crain, Stephen; and Pietroski, Paul (2001). Nature, nurture, and Universal Grammar. Linguistics and Philosophy 24(2), 139-186.

-(2002). Why language acquisition is a snap. The Linguistic Review 19(1-2), 163186.

Crain, Stephen; and Wexler, Kenneth (1999). Methodology in the study of language acquisition: a modular approach. In Handbook of Language Acquisition, William C. Ritchie and Tej K. Bhatia (eds.), 387-425. San Diego, CA: Academic Press.

Drozd, Kenneth F. (2002). Negative DPs and elliptical negation in child English. Language Acquisition 10(2), 77-122.

Eguren, Luis; and Fernández Lagunilla, Olga (2004). Introducción a una Sintaxis Minimista. Madrid: Gredos.

Fodor, Jerry A. (1975). The Language of Thought. New York: Thomas Crowell.

Fodor, Janet D.; and Crowther, Carrie (2002). Understanding stimulus poverty arguments. The Linguistic Review 19(1-2), 105-145.

Fox, Danny (2000). Economy and Semantic Interpretation. Cambridge, MA: MIT Press.

Friedemann, Marc-Ariel and Rizzi, Luigi (2000). The acquisition of syntax: introduction. In The Acquisition of Syntax. Studies in Comparative Developmental Linguistics, M.-A. Friedemann and Luigi Rizzi (eds.), 1-25. Harlow: Longman.

Futuyma, Douglas (1998). Evolutionary Biology, 3rd ed. Sunderland, MA: Sinauer.

Gavruseva, Elena and Thornton, Rosalind (2001). Getting it right: acquisition of whosequestions in child English. Language Acquisition 9(3), 229-267.

Goodluck, Helen (2001). The nominal analysis of children's interpretations of adjunct PRO clauses. Language 77(3), 494-509.

Goodluck, Helen; Terzi, Arhonto; and Chocano Díaz, Gema (2001). The acquisition of control crosslinguistically: structural and lexical factors in learning to license PRO. Journal of Child Language 28(1), 153-172.

Guasti, Maria Teresa (2002). Language Acquisition: the Growth of Grammar. Cambridge, MA: MIT Press.

Griffiths, Paul E. (2002). What is innateness? The Monist 85(1), 78-85.

Hauser, Marc D.; Chomsky, Noam; and Fitch, W. Tecumseh (2002). The faculty of language: what is it, who has it, and how did it evolve? Science 298, 1569-1579. 
Hoekstra, Teun and Kooij, Jan G. (1988). The innateness hypothesis. In Explaining Language Universals, John A. Hawkins (ed.), 31-55. Oxford: Blackwell.

Hornstein, Norbert (2001). Move! Oxford: Blackwell.

Hornstein, Norbert and Lightfoot, David (1981). Introduction. In Explanation in Linguistics, Norbert Hornstein and David Lightfoot (eds.), 9-31. London: Longman.

Hyams, Nina (2002). Clausal structure in child Greek: a reply to Varlokosta, Vainikka and Rohrbacher and a reanalysis. The Linguistic Review 19(3), 225-269.

Jaeggli, Osvaldo (1986). Passive. Linguistic Inquiry 17(4), 587-622.

Jordens, Peter (2002). Finiteness in early child Dutch. Linguistics 40(4), 687-765.

Lasnik, Howard (1999a). Minimalist Analysis. Malden, MA, and Oxford: Blackwell.

- (1999b). Chains of arguments. In Working Minimalism, Samuel D. Epstein and Norbert Hornstein (eds.), 189-215. Cambridge, MA: MIT Press.

- (1999c). On feature strength: Three minimalist approaches to overt movement. Linguistic Inquiry 30(2), 197-217.

Legate, Julie Anne and Yang, Charles D. (2002). Empirical re-assessment of stimulus poverty arguments. The Linguistic Review 19(1-2), 151-162.

Lightfoot, David (1999). The Development of Language. Acquisition, Change, and Evolution. Oxford: Blackwell.

Longa, Víctor M. and Lorenzo, Guillermo (2001). Derivación y Representación: su Alternancia Cíclica en la Teoría de la Gramática. Noia, A Coruña: Editorial Toxosoutos.

Lorenzo, Guillermo (2001). Comprender a Chomsky. Introducción y Comentarios a la Filosofia Chomskyana sobre el Lenguaje y la Mente. Madrid: Antonio Machado Libros.

Lorenzo, Guillermo; and Longa, Víctor M. (2003). Minimizing the genes for grammar: the Minimalist Program as a biological framework for the study of language. Lingua 113(7), 643-657.

Lust, Barbara (1999). Universal Grammar: the strong continuity hypothesis in first language acquisition. In Handbook of Language Acquisition, William C. Ritchie and Tej K. Bhatia (eds.), 111-155. San Diego, CA: Academic Press.

Maclaurin, James (2002). The resurrection of innateness. The Monist 85(1), 105-130.

Matsuo, Ayumi and Duffield, Nigel (2001). VP-ellipsis and anaphora in child language acquisition. Language Acquisition 9(4), 301-327.

McCloskey, James (2002). Resumption, successive cyclicity, and the locality of operations. In Derivation and Explanation in the Minimalist Program, Samuel D. Epstein and T. Daniel Seely (eds.), 184-226. Oxford: Blackwell.

McKee, Cecile and McDaniel, Dana (2001). Resumptive pronouns in English relative clauses. Language Acquisition 9(2), 113-156.

Newmeyer, Frederick J. (1998). Language Form and Language Function. Cambridge, MA: MIT Press.

O'Neill, John Herbet (1997). Means of control: deriving the properties of PRO in the Minimalist Program. Unpublished doctoral dissertation, Harvard University.

Panagiotidis, Phoevos (2002). Pronouns, Clitics and Empty Nouns. Pronominality and Licensing in Syntax. Amsterdam and Philadelphia: John Benjamins.

Petinou, Kakia and Terzi, Arhonto (2002). Clitic misplacement among normally developing children and children with Specific Language Impairment and the status of Infl heads. Language Acquisition 10(1), 1-28.

Pinker, Steven (1989). Learnability and Cognition: The Acquisition of Argument Structure. Cambridge, MA: MIT Press.

Pullum, Geoffrey K. and Scholz, Barbara C. (2002). Empirical assessment of stimulus poverty arguments. The Linguistic Review 19(1-2), 9-52. 
Rizzi, Luigi (2000). Remarks on early null subjects. In The Acquisition of Syntax. Studies in Comparative Developmental Linguistics, Marc-Ariel Friedemann and Luigi Rizzi (eds.), 269-292. Harlow: Longman.

Sampson, Geoffrey (2002). Exploring the richness of the stimulus. The Linguistic Review 19(1-2), 73-104.

Samuels, Richard (2000). Massively modular minds: the evolutionary psychological account of cognitive architecture. In Evolution and the Human Mind: Modularity, Language and Meta-Cognition, Peter Carruthers and Andrew Chamberlain (eds.), 13-46. Cambridge: Cambridge University Press.

Santelmann, Lynn; Berk, Stephanie; Austin, Jennifer; Somashekar, Shamita; and Lust, Barbara (2002). Continuity and development in the acquisition of inversion in yes/no questions: dissociating movement and inflection. Journal of Child Language 29(4), 813-842.

Segal, Gabriel (1996). The modularity of theory of mind. In Theories of Theory of Mind, Peter Carruthers and Peter K. Smith (eds.), 141-158. Cambridge: Cambridge University Press.

Skarabela, Barbara; Fish, Sarah; and Do, Anna H.-J. (eds.) (2002). Proceedings of the 27th Annual Boston University Conference on Language Development, 2 vols. Somerville, MA: Cascadilla Press.

Snyder, William; Senghas, Ann; and Inman, Kelly (2001). Agreement morphology and the acquisition of noun-drop in Spanish. Language Acquisition 9(2), 157-173.

Stich, Stephen (1975). The idea of innateness. In Innate Ideas, Stephen Stich (ed.), Berkeley, CA: University of California Press.

Studdert-Kennedy, Michael and Goldstein, Louis (2003). Launching language: the gestural origin of discrete infinity. In Language Evolution, Morten H. Christiansen and Simon Kirby (eds.), 235-254. Oxford: Oxford University Press.

Thomas, Margaret (2002). Development of the concept of "the poverty of the stimulus". The Linguistic Review 19(1-2), 51-71.

Thornton, Rosalind (2002). Let's change the subject: focus movement in early grammar. Language Acquisition 10(3), 229-271.

Thornton, Rosalind and Wexler, Kenneth (1999). Principle B, Ellipsis, and Interpretation in Child Grammar. Cambridge, MA: MIT Press.

Tracy, Rosemarie (2002). Growing (clausal) roots: all children start out (and many remain) multilingual. Linguistics 40(4), 653-686.

Valois, Daniel (2000). Introduction. [Special Issue: Syntaxe et Acquisition du Français Langue Maternelle]. Canadian Journal of Linguistics 45(1-2), 1-5.

Wexler, Kenneth (1998). Very early parameter setting and the unique checking constraint: a new explanation of the optional infinitive stage. Lingua 106(1), 23-79.

-(1999). Maturation and growth of grammar. In Handbook of Language Acquisition, William C. Ritchie and Tej K. Bhatia (eds.), 55-109. San Diego, CA: Academic Press. 